In other words, rational forms of language and thought are acquired throughamong other things - mature examples of the use of actual argumentative linguistic forms in acknowledged texts. These linguistic forms are themselves printed in bold type and so are immediately brought into your focus without a chance to be overshadowed by the interesting topic in which they occur. One learns them visually without effort and without having to understand any theory or rules. One simply learns to use them.

Summing up: this is an understandable and probably quite effective collection of experiences and wisdom concerning good arguments. Chances are high that this approach (to one familiar situation, the situation of uncertain writers) will bring many a writer to a higher level of maturity. The book is probabbly not meant for the mature readers of this journal, but their students would fall under the intended readership.

E. M. BARTH

\title{
ARGUING: EXCHANGING REASONS FACE TO FACE
}

By Dale Hample. Mahwah, N.J.: Lawrence Erlbaum Associates, 2005.

Pp. xiii + 369. ISBN 0-8058-4854-1. US \$99.95 | Special Discount Price \$39.95.

Arguments do not, and cannot, occur without people. They are not naturally occurring things like rocks or bumblebees that are simply out there in the world waiting to be discovered; they depend completely and entirely on humans for their existence. So much is incontestable. Once, however, we move beyond that rather uninteresting point of agreement we reach a wide range of differentiation. Some theorists, such as Willard (1976), claim that arguments cannot be understood in isolation from the actual, particular argument as it happens and where it happens. At the other extreme we have Johnson (2000) who sees written arguments as presented in an editorial or an essay as the "distillate" of argumentation (168). Between these two extremes there is vast continuum of positions regarding the degree to which arguments must be situated and viewed in context in order to be understood and properly analyzed.

Dale Hample, in his book, Arguing: Exchanging Reasons Face to Face, makes it clear in his sub-title where his position lies. Arguments are not only created by people who are arguing, but can only be understood in that context. While static arguments are by no means dismissed or discarded, it is the nature of arguing as it occurs in its natural setting that fascinates Hample. The roots of the very notion of argument are familiar to all of us: "An argument is a conclusion supported by reasons" (1), Hample writes on his very first page. So the traditional root notion of an argument as found, say, in informal logic is not challenged, though past that point the connections to the familiar become more strained. The focus of Hample's book is not so much argument structure, but the motivations we have for arguing, and the psychological and social tools we use for creating and editing arguments. Why do people argue? How do they create their arguments? How do they receive arguments? 
Hample undertakes in this book to both review and use contemporary work in communication theory and social psychology to inform the reader of the available data and theories, on the one hand, and, on the other, to present a person-centred theory of argument that is at once dialectic, rhetorical and interactive. As the book covers a great deal of territory, bringing the reader from an introductory level to a sophisticated understanding of the issues, I will not endeavour to touch all the bases that Hample does. Rather, I want to focus on one or two matters that might be of special interest to those in informal logic. This is not to say that there are parts of the book that are not of interest to everyone in any area of argumentation theory. To the contrary. The book is actually a fascinating and fine addition to the literature, and, aside from an occasionally annoying penchant for short sentences, fairly well written.

Several of the matters that Hample raises would not have made sense to informal logicians working thirty or so years ago, but today far fewer of those issues will be dismissed by far fewer argumentation theorists. Nonetheless, the approach he describes crosses various lines that informal logicians might find uncomfortable. Consider, as an example, the idea of argument editing ( $85 \mathrm{ff}$ ). Here Hample makes clear the difference between the concerns of informal logicians and his own communication theory/social psychological approach. The issues here concern how messages are created, and, especially with regard to how we decide what is said and not said. As a result, for example, issues of politeness and relationship maintenance are relevant and important factors for Hample, while for the usual informal logic approach these matters not only are irrelevant, but do not even exist. Forming a conclusion that is easy for an antagonist to accept by avoiding doing damage to her position may be considered polite by an informal logician, but may also open one up to a charge of equivocation or worse. The Ideal Arguer, from the point of view of informal logic, is one who puts forward the strongest and most direct arguments that the evidence can support. Presumably, two Ideal Arguers in more or less similar situations would offer the same arguments. But even ideal arguers have diverse interests, needs, and, most importantly, goals.

We rarely, Hample says, argue just for the heck of it: "People argue to accomplish things in their daily lives, and the pursuit of these accomplishments is what is salient to the actors. Arguing is an essentially instrumental activity, done with a practical object in mind and almost never done for its own sake..." (35). Of course, as philosophers and argumentation theorists, we tend to argue more than most people, but that comes with the territory; (more on this below). Generally, when people enter into an argument, it is in order to secure some instrumental objective; however, it also necessarily involves juggling a variety of secondary and relational goals. Since we do not argue in a vacuum, but with other people, who those people are and what their feelings are become factors in the process.

In addition to the myriad goals that can influence how an argument is formed, there are also questions of expertise and how one understands the very idea of communication. Hample puts this issue in terms of "frames," of which there are three. The first frame is the instrumental goal (34); the second involves the goals of the other person[s] involved in the argument; the third involves reflecting on the process of arguing itself. That is, the third frame "involves recalling argumentative experiences and abstracting general principles from them" (51). The frames, then, describe different levels of awareness on the part of the protagonist: the greater 
awareness one has of the other person involved in the argument, and the greater awareness one has of the process itself as a common communicative endeavour, the higher the level of the frame one is in. These frames echo Barbara O'Keefe's (1988) theory of Message Design Logic [MDL], wherein arguers subscribe to one of three ways of conceiving communication: the Expressive MDL sees communication as an essentially unedited, artless means of saying what one is thinking; the Conventional MDL understands that communication is a cooperative enterprise that follows rules and procedures; the Rhetorical MDL appreciates that messages can portray personalities, change situations, and create communicative possibilities. Each frame, each MDL, will create different arguments for different people, meaning that there is no one argument, no individual core that is a "good" argument or a "bad" argument. Argument will simply mean different things to different arguers.

Arguments are created by people, and people vary in a multitude of ways. Different arguers will have, as mentioned, different outlooks on what they are doing when they communicate, but also different imaginations, intelligences, creative impulses, and personal needs. When these different arguers produce messages, they all draw on a vast array of distinct histories and perspectives. Hample writes:

\begin{abstract}
A message is not a static production but a dynamic one, and this dynamic nature makes editing such an important topic. Often in studying arguments, researchers look at a written passage or a few paragraphs from a speech, which tempts them into the unexamined assumption that the argument simply popped out, more or less as it appears in print. As introspection reveals, however, the production of an utterance or a sentence is a process that often involves micromomentary impulses, decisions, and changes of direction. (106)
\end{abstract}

Perhaps this explains why Johnson refers to written argument as the "the distillate of argumentation" of argumentation $(2000,168)$. The supposition is, perhaps, that once an argument is preserved in text and removed from the dynamics of discourse, then all of the activities Hample describes can be ignored. And, of course, on can do just that: one can analyse an argument as if it were not created by a human being in the cauldron of the creative process of message production. However, can one really understand it, even critique it, in isolation from that context, that background? Hample's work would suggest not, as witnessed in the following quote.

Redressing the emotional sterility of argumentation studies for the last two millennia is a prospect that should be welcome. Arguing is a human activity, and people are moved by their urges, suffer epiphanies and depressions, and orient to other's emotional expressions during and because of their arguments. To ignore this is to miss a great part of what makes arguing a distinctly personal and humanizing accomplishment. (175)

So, while one can analyze and examine arguments isolated from the source of their production, and while that might have certain value, there is a great deal that can be lost, that can be missed, by doing so. The tools Hample is offering us are different than those you are most familiar with, but, surely, the larger the toolbox, the more flexibility there is in the construction of an analysis. 
There is also something of the guilty pleasure of being a voyeur in reading this book. As a philosopher and informal logician, I have the feeling of peering into someone else's yard to watch how a different family undertakes tasks similar to those with which I am familiar. Indeed, I have often wished I had a communication theory assistant who could rush out and do empirical experiments to verify so many of my speculations about argument. Hample does that in many ways. He reports to us about such matters as TCP, which stands for taking conflict personally, and trait argumentativeness, TA, which measures one's general motivation to argue. These factors influence just how someone perceives arguing as an undertaking. "Individuals high on argumentativeness saw arguing as a way of reducing conflict, whereas those scoring low regarded it as something that escalates disagreements" (28).

Considering this information, I suspect that the majority of philosophy majors and scholars are somewhat low in TCP and high in TA: we can argue without getting upset, and find arguing fairly enjoyable and not stressful. Most of us, in fact, have to learn early in our careers that the techniques and the hair trigger move to argue do not carry over well into family and, frequently, non-collegial social life. We, as a group, consider failure to examine and argue every statement we hear, to be at best sloppy and at worst condescending. We learn, usually the hard way, that our spouses, partners and friends do not always share that perspective. More seriously, people with a high TCP and a low TA score will be reluctant to argue unless there is some strong motivation. Consider, if you will, what impact this has on other theories, such as Johnson's dialectical tier. What happens when one has a responsibility to argue and consider various options and critiques, but one is emotionally loathe to do so. Similarly, in the Pragma-Dialectic model, one is often obligated to respond according to a rule of critical discussion, but one may not, out of fear rather than out of malice or even error. E.g., according to one study cited by Hample, "The largest number of arguments appeared when an actor high in argumentativeness conversed with a person low in argumentativeness, and the lowest number appeared when two people low in argumentativeness interacted" (180). In the first case, there was little to stop the high trait argumentativeness individual from making many arguments, and in the second there was no encouragement from either side. As a further example, Hample cites his own informal in-class survey: "Suppose...that you were in an argument with a romantic partner, and you were losing badly even though you knew you were right. Something occurs to you that would absolutely win the argument, but would hurt your partner's feelings a lot. Would you say it anyway" (228)? The result in the class is usually 5050 , with half willing to put forward the argument and the other half not.

Of course, there is always a question about the research and the data. One cannot review a book on communication theory and social psychology without at least mentioning the potential for well-known errors and traps that await researchers. So much of what we know about the world is based on white, middle class university students who have been enticed into experimental participation. I am pleased to report that Hample is aware of this, and distinguishes in a variety of places where the samples used varied with respect to background, and where they did not. This does not eliminate the problem, but highlights it when necessary.

A final point I would mention has to do with the perennial issue of eristic arguments. If, as some would fear, communication theory and social psychology only gauge effectiveness, then what is the moral status of argument as construed 
as a rhetorical enterprise? Hample is quite clear that, "Effectiveness...should never be a solitary consideration. A good argument must also be ethical and moral" (55). But, he admits, "In an argumentative exchange two of the more effective things a person can do are to lie or to threaten" (54). What, however, is to drive the ethical and moral imperative if the rhetorical ideal of effectiveness is not to be completely dominant? Interestingly, it is the very idea of being effective that comes with its own limits. When we are presented with arguments, we are not merely passive listeners. We are also judges and evaluators.

What conclusions can be drawn about people's construal of others' arguments? First, individuals are (or at least can be, when properly motivated) very sensitive to content. All the research gives a prominent perceptual place to reason and evidence. An immediate and salient feature of an incoming message is whether it is coercive or manipulative, and whether it makes an affiliative appeal..., whether it is polite, and whether it is pointed or open ended. Third, these and other studies give some evidence that others' arguments are received as immediately agreeable or disagreeable... This judgment is based partly on sociality and prior attitude but also partly on the degree to which the content of the message seems forcible and probative. (199)

In short, the quality of an argument is one of the things that makes it effective. We are, mostly, not impressed by arguments that are bullying, rude, or that ignore evidence. This also provides motivation for education regarding arguments and what makes them good and bad. As Hample concludes, "The arguers, not the arguments, possess the energy for public transformation. An argument can be a vehicle for change, but the changers are always, and only, the arguers" (334).

I am pleased to recommend this book, no, urge its reading by all those working in argumentation theory. If you are not already familiar with the results and research going on in the empirical fields of communication theory and social psychology, then it will be an eye-opener, and a careful one at that. If you are in that field then Hample's application of the material to argumentation as a process undertaken by arguers will be a useful addition to your repertoire. We have been fortunate in argumentation theory that a number of valuable books have been produced in the last 10 or 15 years, and I am pleased to say that Hample's book is an important contribution to that production.

\section{References}

Johnson, R. H.: 2000, Manifest rationality : a pragmatic theory of argument. Mahwah, N.J. ; London: Lawrence Erlbaum Associates. ISBN: 0805821740.

O'Keefe, B.: 1987, "The Pursuit of Multiple Objectives in Face-to-Face Persuasive Interactions: Effects of Construct Differentiation on Message Organization." Communication Monographs 54:396-419.

Willard, C. A.: 1976, "On the Utility of Descriptive Diagrams for the Analysis and Criticism of Arguments." Communication Monographs 64:308-319. 